\title{
Analysis of trading volume and its use in prediction future price movements in the process of maximizing trading earnings
}

\author{
Jan Chutka ${ }^{1, *}$, Filip Rebetak $^{1}$ \\ ${ }^{1}$ University of Zilina, The Faculty of Operation and Economics of Transport and Communications, \\ Department of Economics, Univerzitna 1, 01026 Zilina, Slovakia
}

\begin{abstract}
.
Research background: When we start looking for tools that could give a trader a certain trading advantage, we will certainly come across the problem of analysing the trading volume. This is an advanced type of analysis where the primary price chart of the underlying asset is not analysed, but traders focus on the volume of trades that have been executed at certain price levels. Although it may seem like an innovative method, this type of analysis has been used for several decades. In our article, we elaborated the theoretical basis of the analysis of trading volume as a tool for predicting the movement of prices of financial instruments.

Purpose of the article: The aim of our article is to explore the possibilities, methods and procedures of analysis of trading volumes and the possibilities of their use in maximizing earnings from trading of financial instruments.

Methods: We used formal methods such as analysis and synthesis of theoretical findings and others.

Findings \& Value added: Based on the study of the analysis and synthesis of theoretical data, we identified and described the possibilities of using the analysis of trading volume in the process of predicting the price movements of financial instruments. We consider the aim of the article to be fulfilled and we believe that it will be a valuable contribution in the field of research on this issue.
\end{abstract}

Keywords: volume analysis, trading, prediction, trading earnings

JEL Classification: $G 12, G 15, G 17$

\section{Introduction}

In a deeper study of the methods of analysis used today in the financial market, we will undoubtedly come across efforts to use the analysis of trading volumes as a tool to predict future price movements of financial instruments. In general, we can say that the analysis of trading volumes is considered as an advanced and complex prediction tool and is not widespread among investors and traders. However, in today's age of modern technology, we see huge progress in the trading of financial markets in the software equipment of traders, which allows the efficient and easy use of even complex and advanced methods. In our article we will deal in more detail with the analysis of trading volumes in the financial

\footnotetext{
*Corresponding author: jan.chutka@fpedas.uniza.sk
} 
markets, we will describe the individual procedures and their use in trading practice and then identify the basic advantages and disadvantages of these methods.

\section{Analysis and prediction}

International financial markets have undergone various turbulent changes in recent decades. Globalization, and especially scientific and technological progress in information technology, has meant rapid development in the world of finance. The very existence of financial markets and trading in financial market derivatives foreshadow efforts to predict the development of these assets. The goal of predicting the development of financial instruments may not be, as san and at first glance may seem, exchange rate gain, but also hedging positions and effective portfolio management. The effort to predict developments in the financial markets can be traced back to ancient times. Paragraph 48 of the Chamuraphi Code mentions that in the case of non-harvest, when farmers have losses, the persons with losses (i.e. not only farmers) do not have to pay interest (in the form of grain) for one year. According to M. Stupavsky, this is one of the first mentions of options at all. One of the first attempts to predict and use a certain strategic approach can be found in ancient Greece. This early derivative trade was carried out by the philosopher Thales of Miletus (624 BC - $548 \mathrm{BC}$ ). His goal was to prove that using reason can easily get rich. Based on his knowledge of astronomy, he assumed a rich olive harvest, so he bought the option to rent olive presses. His expectations came true and his speculation became lucrative. In the modern world of information technology, investors and traders have a choice of a wide range of financial assets, instruments and their derivatives, as well as a large number of procedures and methods that help them predict their price movements $[1$, 2]. In the modern understanding of trade, the main goal of every trader is to generate the greatest possible profit with the highest possible efficiency. In principle, a trader cannot significantly influence what is happening in the market and therefore focuses on the aspect of trading that he can manage. One of the most important parts of profitable trading is effective risk management. On the stock exchange, a trader faces various types of risks such as financial risk, liquidity risk, company bankruptcy risk and many others. Therefore, an integral part of profitable trading is the effective identification of risks, their management and minimization of their potential impact [3-6].

\section{Trading volume analysis}

In general, we can say that the main goal of any method of analyzing the prices of financial instruments is to provide the trader with information on the basis of which he can effectively predict future price movements of the financial instrument. Such methods are an integral part of the operation of all types of market participants such as banks, financial institutions, intermediaries in the financial markets [7, 8]. Trading volume analysis can be included among the newer and more interesting methods of financial instrument analysis. This type of analysis is based on the very microeconomic relationship between supply and demand. The interaction of these factors then defines the relationship between price and volume. In our view, the trading volume analysis method is closer to examining the very nature of financial markets than other methods, because this type of analysis directly examines the process of creating an equilibrium price of a financial instrument in relation to trading volume regardless of why market participants traded as traded. Many other methods focus on the analysis of impulses and the motive on the basis of which traders are to behave in a certain way. However, we know from practice that when a trader is exposed to a stressful situation, we cannot accurately identify whether his behaviour is rational or 
irrational. If we analyse the motive and stimulus for a certain type of business behaviour, the identification of rationality or irrationality is essential. Therefore, we can say that the analysis of trade volume is based on two basic mechanisms. From the market mechanism, the interaction of supply and demand and from the auction process on the financial market $[9,10]$.

\subsection{Interaction of supply and demand}

A market mechanism is a system that involves the relationship between producers and consumers. It is a set of relationships and processes that help the coordination of free individual economic entities in the allocation of production factors, prices of goods and the like, through the transmission of information through the price system. The market mechanism works automatically depending on the level of demand, supply and the effect of price. Demand represents the amount of goods that buyers are willing and able to buy depending on the price. Demand is an interdependence between the quantity of goods and services required $(\mathrm{Q})$ and their price $(\mathrm{P})$. The lower the price of the goods, the larger the quantity required, and the higher the price of the goods, the smaller the quantity people will be willing to buy from it. It is important to be aware of the difference between demand and quantity. Demand expresses the behaviour of buyers with respect to price, and the term required quantity expresses the connection and relationship to a certain price, which is only one quantity (Q). Another important entity that enters the market of goods and services are manufacturers (companies, entrepreneurs), who decide at their own discretion what they will produce and in what quantities. Here, producers act as sellers who offer goods. An offer represents a quantity of goods and services that are sold willing and able to sell depending on the price. The supply curve expresses the relationship between the price and the quantity offered, which producers are willing to produce the goods and then sell. The law of increasing supply applies here, in which the production of goods and also the offered quantity increase with the increase of the price and vice versa [11]. Equilibrium is a term taken from economic theory in physics. In economic theory, it expresses the general situation when market subjects or groups of actors forming markets have no reason to change their behaviour [12]. It is a natural feature of the economic system that it develops into the so-called steady state, $i$. to a state where the market price has stabilized at a price level at which producers are willing to produce a given quantity of a given good and buyers are willing to buy a given quantity of that good at a given price level [13]. In other words, we can say that this situation occurs at the intersection of the demand and supply curves, because there the demand quantity is equal to the quantity offered and so there is neither a surplus nor a shortage of the goods or services on the market.

\subsection{Auction process on financial markets}

In his study, Seildmayer devoted a great deal of time to understanding the structure of the market. He understood the structure of the market as phenomena that occur in the market and have certain recurrences. One of his conclusions was that the market has two phases, balance and imbalance. From this original idea, he further developed his research and ultimately defined the structure of the market in six points that have a logical sequence. The classic auction differs from the auction on the financial market in the auction process. While in a regular auction the participants in the auction are only able to buy the product, in an auction on the financial market the auction has two directions and the participants in the market have the opportunity to both buy and sell the given financial instrument. The purpose of the stock exchange is the same as in any other auction, to enable and mediate individual trades. By its very nature, the market strives for the highest possible efficiency 
and thus to fill orders in the direction where there is the largest volume. The moment one auction ends on the financial market, the other starts in the opposite direction. Complexity is created by a number of market participants who trade on the basis of different ideas, approaches and strategies, on differently sized accounts, with different mental or psychological settings. Such traders have different goals and trade in different time horizons. Different time horizons create different opportunities and consequently different fair prices. A fair price is defined as the price level that attracts the largest number of buyers and sellers, and thus the largest volume of completed trades is generated at this level. The fair price has a different meaning for different time periods [14].

\section{Methods of trading volume analysis}

\subsection{Market profile}

Market profile is a method that aims to monitor and analyse the structure of the development of the price of a financial instrument. This method is based on Time price opportunity (TPO). The individual TPO market profile is displayed as alphabetical letters. Each TPO is plotted on the price levels at which the market traded during a predefined interval. The most commonly used is a 30 minute TPO rendering interval. At the end of this interval, the next TPO displayed by another letter of the alphabet will start to be drawn immediately. In this way, the market profile can display the specific structure of the market and the trader has a clear idea of the price range in which the trade was traded during a specific time interval. The market profile provides the trader with the following specific price areas and identifies them in the price chart $[14,15]$ :

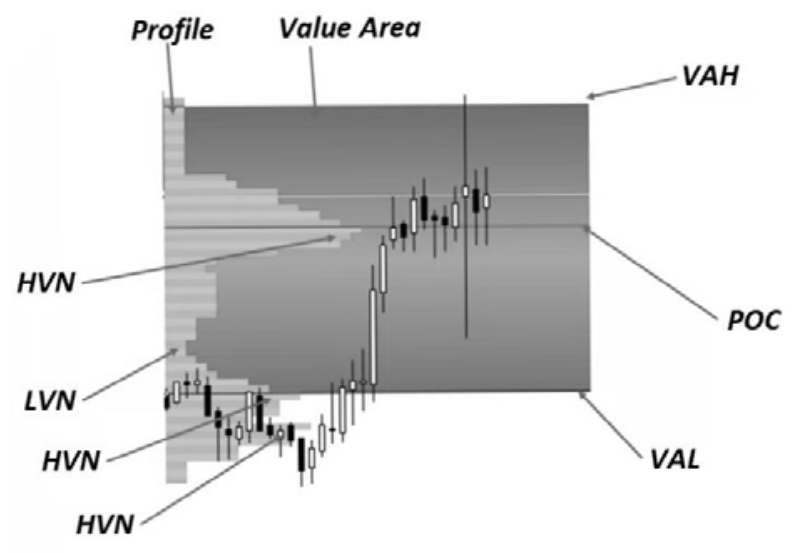

Fig. 1. Description of data from the market profile

- Profile - market profiling according to the time spent at a certain price, or according to the size of the volume.

- Value Area - or the area of value, which is the area where the market has spent $70 \%$ of its time (or where $70 \%$ of the volume has been traded).

- VAH - Value Area High, the upper edge of the value area.

- VAL - Value Area Low, the lower edge of the value area.

- POC - Point Of Control, or fair price (the market perceives this price as fair).

- HVN - High Volume Node, ie an area of increased interest of traders.

- LVN - Low Volume Node, ie an area of low interest of traders. 


\subsection{Volume profile}

The volume profile contains a histogram of the volumes realized by the trade at individual prices of financial instruments. The histogram thus graphically shows us the records of realized trades in dependence on the price levels of financial instruments. At the price levels at which a large number of orders were realized, a longer line at the respective price level is graphically recorded in the histogram. Conversely, at price levels with a low volume of trades, short bars are displayed at the respective price levels. By default, the length of the line defines the size of the realized volume of trades at a given price level. In a clear form, the trader sees at what price levels there was interest in trading and, conversely, at what price levels the willingness of market participants to execute their orders was absent $[16,17]$.
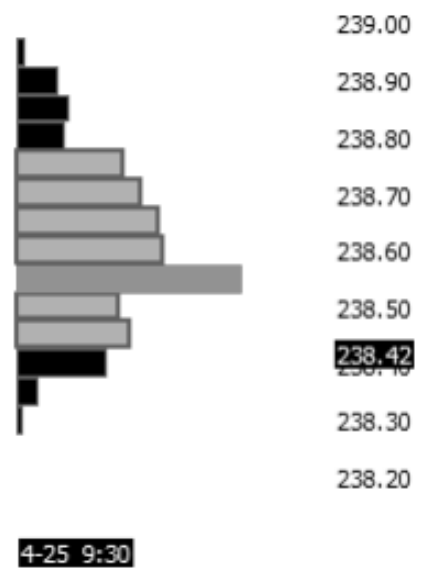

Fig. 2. Example of a volume profile

Volume profile can be characterized as an offshoot of the classic market profile. It is again an alternative method of displaying the classic price chart, but in the context of the volume of trades, as the name suggests. The market profile as such, as mentioned above, shows the development of the price over time and is divided into time periods. Eventually, a shape similar to the Gaussian curve of the normal distribution emerges, from which it is easy to see at which price levels the price moved the longest. The volume profile has a very similar representation, only it does not consist of letters. It is a continuous curve, again often similar to Gauss's, which interprets how many trades were made at different price levels over a given period of time (for example, one day). The basic information that the volume profile generates is the division of price levels into two areas. These are areas with a high volume, which are recognizable in the graph as convex, and areas with a low volume of realized trades, which, on the contrary, are areas where the profile looks curved. The market tends to react very differently in both of these areas. An area with a high volume of trades is referred to as a value area, ie an area of value, as in the case of a market profile. The market tends to stay in this area and oscillate here and there, because a large part of supply and demand is satisfied. According to the normal distribution, the value area includes approximately $70 \%$ of the chart spread as well as the same percentage of total trades executed. Low volume areas are called reversal areas. Here, the price is not accepted by a large number of traders, so only a small percentage of total trades are realized here. The market then tends to reject these areas, as the name suggests. In practice, in these areas, the price either bounces back or trades quickly to another area of value. Here, agreement with the market profile can be observed. These are areas where the price only lasts for a short time, ie they contain only one or two letters (periods) $[15,18]$. 


\section{Results}

Based on the study of the analysis and synthesis of theoretical data in the subject area, we can say that the idea of analysing trading volumes depending on price levels through the volume profile is logically based on the Steidlmayer market profile itself. Although these two methods may seem almost identical to us, there is a significant difference between them. The market profile does not analyse the trading volume, it focuses on the structure of the market and its price development over time. It graphically captures only the commercial price range of the financial instrument in a predefined time horizon. On the other hand, the volume profile itself does not deal with market structures but only with the volume of trades at certain price levels. Graphically, based on the histogram, it shows us the distribution of trading volume in a certain price and time interval. A comparison of these two methods shows that their graphical representation and shape of the graph are very similar. This fact may be the result of a high correlation between the size of the trading volume and the length of time the price has spent at given price levels. From a logical point of view, we can also find this theoretic causality, because the statement that the longer a lot is traded on a given price, the more volume is traded on it, is definitely true, but the flow of orders over time can certainly not be considered linear and this relationship can be disrupted at any time. A huge advantage of using the volume profile to predict future price movements of financial instruments is the fact that we are getting to the very micro-level of market functioning. If it is true that the price of a financial instrument can change only in the event of a market imbalance and thus based on the interaction between demand and supply, then the analysis of the realized volume paves the way to identify the equilibrium price, deficit and excess of the financial instrument at a given time.

\section{Discussion}

A number of interesting contributions have already been published in the area of business volume research. Our paper points to a very important fact, namely the connection between microeconomic theory and the prediction tool itself. An important fact is the knowledge that the indicator itself, which offers the trader the opportunity to monitor the structure of the execution of orders at individual price levels, is based on these valid microeconomic laws. It would be interesting to further research aimed at testing the effectiveness of the market profile's predictive ability on different time frames and on different types of financial instruments and their derivatives. The disadvantage of the market profile indicator is the fact that the trader is forced to delimit the analyzed area in a certain way and thus estimate the time and price interval of the analysis. The problem may arise if the trader sets limits that do not correspond to the current market situation. An analysis that is too large to distort the prediction of future price movements could be analyzed, or an analysis that is too small to fail to predict future price movements because it lacks the conditional variables.

\section{Conclusion}

The aim of our article was to explore the possibilities, methods and procedures of analysis of trading volumes and the possibilities of their use in maximizing earnings from trading of financial instruments. The first chapter of our article is devoted to the compilation of the theoretical apparatus needed for further research. In the following chapters we deal with a detailed description of methods of analysis of trading volumes and their use in trading. In the last chapter of our paper, we compared the advantages and disadvantages of the described methods and procedures of analysing of trading volumes. We consider the aim of 
the article to be fulfilled and we believe that it will be a valuable contribution in the field of research on this issue.

The paper is an output of the science project VEGA 1/0210/19 Research of innovative attributes of quantitative and qualitative fundaments of the opportunistic earnings modelling.

\section{References}

1. Chance, Don M. (1998). Essays in Derivatives: A Brief History of Derivatives. John Wiley \& Sons, New York.

2. Stupavsky, M. (2007). It started with grain and ended with the weather. Retrieved from: http://www.penize.cz/19026-zacalo-to-obilim-a-zatim-skoncilopocasim

3. Abughniem, M. S., Hamdan, A. (2019). Corporate sustainability as an antecedent to the financial performance: an empirical study. Polish Journal of Management Studies, 20(2), 35-44.

4. Fialova, V., Folvarcna, A. (2020). Default prediction using neural networks for enterprises from the post-soviet country. Ekonomicko-manazerske spektrum, 14(1), 4351.

5. Valaskova, K., Kliestik, T., Kovacova, M. (2018). Management of financial risks in Slovak enterprises using regression analysis. Oeconomia Copernicana, 9(1),105-121.

6. Valaskova, K., Kliestik, T., Svabova, L., Adamko, P. (2018). Financial Risk Measurement and Prediction Modelling for Sustainable Development of Business Entities Using Regression Analysis. Sustainability, 10(7), 2144.

7. Kliestik, T., Misankova, M., Valaskova, K., Svabova, L. (2018). Bankruptcy prevention: new effort to reflect on legal and social changes. Science and Engineering Ethics, 24(2), 791-803.

8. Rahman, A., Rozsa, Z., Cepel, M. (2018). Trade Credit and Bank Finance - Evidence from the Visegrad Group. Journal of Competitiveness, 10(3), 132-148.

9. Vrbka, J., Nica, E., Podhorska, I. (2019). The application of Kohonen networks for identification of leaders in the trade sector in Czechia. Equilibrium. Quarterly Journal of Economics and Economic Policy, 14(4), 739-761.

10. Zhuravleva, N. A., Elvira, N., Durana, P., (2019). Sustainable Smart Cities: Networked Digital Technologies, Cognitive Big Data Analytics, and Information Technologydriven Economy, Geopolitics, History, and International Relations, 11(2), 41-47.

11. Lisy J., (2005). Economy in the new economy, Bratislava, Iura Editio.

12. Holkova, V., Veselkova, A., (2008). Microeconomics, Bratislava, Sprint Dva.

13. Fendek, M., Fendekova, E., (2008). Microeconomic analysis, Bratislava, Iura Edition.

14. Chicago Board of Trade, (1996), A Six-part Study Guide to Market Profile. Chicago USA.

15. Turek, L., (2012) Market profile: ace in trader's hand. Prague, Czechwealth.

16. Chong, T.T.L., Wu, Y., Su, J., (2020). The Unusual Trading Volume and Earnings Surprises in China's Market, Journal of risk and financial management, 13(10), 244.

17. Sampath, A., Gopalaswamy, A.K., (2020), Intraday Variability and Trading Volume: Evidence from National Stock Exchange, Journal of emerging market finance, 19(3), 271-295.

18. Ante, L., (2020), Bitcoin transactions, information asymmetry and trading volume, Quantitative finance and economics, 4(3), 365-381. 